Universität Bielefeld Faculty of Business Administration and Economics

Working Papers in Economics and Management

No. 02-2013

February 2013

\title{
Private Labels and International Trade: Trading Variety for Volume
}

\author{
Emily Blanchard \\ Tatyana Chesnokova \\ Gerald Willmann
}




\title{
Private Labels and International Trade: Trading Variety for Volume
}

\author{
Emily Blanchard; Tatyana Chesnokova $†$ and Gerald Willmann ${ }^{\ddagger}$
}

February 10, 2013

\begin{abstract}
This paper explores the role of pooled-producer, e.g. private label, trade intermediation in shaping the range and diversity of exports. Direct sales maintain a firm's unique product characteristics ('brand equity'), whereas trade through an intermediary can take two forms - either a wholesaling arrangement that (also) maintains the exporter's unique brand but imposes a higher marginal cost (via double marginalization), or a 'private label' contract under which the firm's product is pooled with other firms' output and re-sold under a new private label brand created by the intermediary. This paper focuses on the latter, and shows that the availability of the private label option results in greater total export volumes and lower average prices for consumers, but fewer independent varieties available in equilibrium. Welfare implications are mixed: consumers trade variety for volume, firms face greater competition from the new pooled-products, and intermediaries capture much of the gains from trade.

Keywords: Private Labels, Export Mode, Intermediaries, Heterogeneous Firms, International Retailers
\end{abstract}

JEL Classifications: F13, F16, D72, E60

*Tuck School of Business at Dartmouth College, emily.blanchard@tuck.dartmouth.edu †School of Economics, The University of Adelaide, tatyana.chesnokova@adelaide.edu.au $\ddagger$ Department of Economics, Bielefeld University and IfW Kiel, gwillmann@wiwi.uni-bielefeld.de. 


\section{Introduction}

Economists are acutely attentive to barriers to international trade and economic openness, yet concerns over international market access focus almost exclusively on physical and political trade costs: tariffs and non-tariff barriers, and the transportation costs associated with physically moving products to market. Until recently, remarkably little attention has been afforded to the commercial realities of international market access - the role and potential failure of the market mechanisms through which exporters in one country reach consumers in another country, whether through direct shipments, wholesalers, product-sourcing arms of international retailing firms or other intermediated trade channels.

In this paper, we join a small but rapidly growing literature in arguing the importance of intermediaries in trade. Our key contribution is to point out that not only do intermediaries shape firm's exporting decisions (which firms export and whether they ship directly or indirectly), but also, crucially, that intermediation may fundamentally change the characteristics of exported products. We suggest that there are two distinct forms of trade intermediation, with very different implications for welfare and policy. The conventional notion adopted by the existing literature considers the role of intermediary as a go-between that reduces the average cost of transportation for potential exporters, either by resolving an information asymmetry or incomplete contracts problem, ${ }^{1}$ or by economizing on trade (or search) costs, ${ }^{2}$ but does not otherwise change the product shipped abroad. We agree that a great deal of trade intermediation - what one might term 'simple wholesaling' - falls into this category.

Conspicuously absent from existing work (with a few exceptions noted momentarily) is a recognition of the potential for transformative trade intermediation, whereby the exported product is fundamentally changed by the process of intermediation. We are particularly interested in the potential for 'pooled-producer' sourcing by intermediaries - the practice through which a given intermediary sources products from multiple independent producers to subsequently rebrand under a new umbrella label completely divorced from the manufacturer's identity and firm-specific characteristics - what the marketing literature calls 'brand equity'. So-called 'private label' brands sold by major international retailers (for example, Circo (Target), Sam's Choice (Wal-Mart), or Kirkland Signature (Costco)) are one possible manifestation of pooledproducer products, but we suggest the phenomenon is broader than simply house brands sold by

\footnotetext{
${ }^{1}$ See Rauch and Watson (2004), Feenstra and Hanson (2004), Felbermayr and Jung (2008), and Felbermayr and Jung (2009)

${ }^{2}$ See Blum, Claro, and Horstmann (2010), Head, Jing, and Swenson (2010), Antràs and Costinot (2011), Ahn, Khandelwal, and Wei (2012), and Akerman (2010).
} 
major retailers. ${ }^{3}{ }^{4}$ Indeed, we posit that these sorts of de-branded arms-length transactions may be one form of the upstream end of the "Carry-Along Trade" phenomenon recently identified by Bernard, Blanchard, Vandenbussche, and VanBeveren (2012). Hereafter, we take some liberty with terms, and use 'private label' and 'pooled-producer' interchangeably, with the express recognition that in practice, private label brands constitute only a subset (but the most clearly observable) form of pooled producer intermediation.

Our focus in this paper is the potential for product homogenization via reduced product differentiation. To that end, we develop a formal thought experiment to explore the potential practical implications of pooled-producer sourcing for the scope and variety of traded products. Given the near universal use of 'love-of-variety' constant elasticity of substitution (CES)-type preferences in the trade literature, the implied welfare implications of product homogenization through intermediated trade are immediate. We readily acknowledge the additional (but essentially orthogonal) potential implications for vertical quality adjustments in response to intermediation. See Dasgupta and Mondria (2011) for a careful treatment in a similar heterogenous firms framework, and Iacovone, Javorcik, Keller, and Tybout (2011) for another perspective. Along a somewhat different line, Bai, Krishna, and Ma (2012) develop and find empirical support for a structural model in which trade intermediation may reduce dynamic market learning potential for exporters relative to direct exporting. Indeed, to the extent that intermediation comes at the expense of exporters' brand equity, our model suggests an additional mechanism complementary to their strong empirical findings.

A wider body of existing empirical work demonstrates both the importance of intermediaries in trade, and the systematic variation in intermediary involvement across sectors and trading partners. Using detailed firm-level trade and transactions data for the U.S., Bernard, Jensen, Redding, and Schott (2010) find that intermediaries are disproportionately involved in trade with lower wage countries (most conspicuously China) and in consumer goods sectors such as agricultural products, clothing, and footwear. Ahn, Khandelwal, and Wei (2012) and Bai, Krishna, and Ma (2012) find similar patterns for China, Akerman (2010) for Sweden, and Blum,

\footnotetext{
${ }^{3}$ In the only other work on private labels in the economics literature of which we're aware, Mills (1995) and Gabrielsen, Staahl, and Sörgard (2007) analyze the vertical structure consisting of a manufacturer and a retailer, both being monopolists, where retailer considers an introduction of a private label product with exogenously given lower quality. The main question in these papers is how private label introduction affects the division of profits between manufacturer and retailer. For a review of the literature see Bergès-Sennou, Bontems, and Réquillart (2004).

${ }^{4}$ Note that our definition of the the term 'private label' is broader than that customarily used by the marketing literature (which typically limits 'private label' to include only house label brands sold by major retailers. In our context, 'private label' refers to any pooled-producer contract in which an intermediary acts as a form of aggregator for manufacturers.
} 
Claro, and Horstmann (2010) for South America. ${ }^{5}$ At the firm level, evidence is broadly suggestive that the biggest, most productive firms export directly, while the majority of (typically much smaller) exporting producers use intermediaries on one or both sides of the border before reaching foreign consumers. Broadly speaking, these studies suggest the intermediaries are most involved in trade with lower-wage countries, less differentiated products, and smaller exporters - trends that reflect marked similarity to the pattern of growth in private label products.

Less well-known are the trends in pooled-product sourcing. Private label products - generic, explicitly non-manufacturer branded products typically sold under international retailers' house brands - are just a subset of the broader 'pooled-producer' phenomenon, but they are the most (perhaps only) cleanly measurable class of pooled-producer products, and so we focus on them here. According to ACNielsen (2005), private label (PL) products are widespread and growing: 6 On average, private label sales make up roughly $17 \%$ of sales at surveyed retailers (supermarkets, hypermarkets, mass merchandizers and some drug- and convenience stores), although regional variation is considerable: emerging markets have experienced the largest growth of PL products at 11 percent per annum, while the share of PL products in Europe has been growing at a more modest 4 percent per year. ${ }^{7}$ PL shares in consumer sales also vary systematically across product categories: less differentiated products have higher PL shares, while more differentiated products have little PL market activity. ${ }^{8}$ Unsurprisingly, PL products are less expensive than their manufacturer-branded counterparts: on average, PL products are priced $31 \%$ lower. $^{9}$

Our paper posits a link between pooled-producer sourcing and trade intermediation, and ties the prevalence of private label exports to fundamentals (market size, preferences, and costs of exporting). We build a tractable heterogeneous firms model of intermediated trade with pooled-producer (private label) contracts. In the existing literature, intermediaries offer simple wholesale arrangements that leave the manufacturer's inherent product characteristics untouched and perfectly observable to the consumer; thus the role of the intermediary is simply to reduce the (average) net cost of reaching consumers either by resolving any informational asymmetry

\footnotetext{
${ }^{5}$ In related work, Head, Jing, and Swenson (2010) test the impact of multinational retailers' local Chinese operations and subsequent export activity from China, while Basker and Van (2010a) and Basker and Van (2010b) consider the impact of Wal-Mart on U.S. imports from China

${ }^{6}$ The ACNielsen (2005) sample includes 38 countries and 80 categories.

${ }^{7}$ A 2011 Survey in 'Private Label Magazine' reported similar figures for individual retailers: last year, PL sales made up $18 \%$ of revenue at Wal-Mart, $24 \%$ at Costco, and $30 \%$ at Target Corp. stores. (Private.Label.Magazine (2011))

${ }^{8}$ For example, the highest PL shares are in refrigerated food (32 percent) and paper, plastic \& wraps (31 percent), while the lowest PL shares are in cosmetics (2 percent), ACNielsen (2005).

${ }^{9}$ There is substantial variation in the price differential between PL and manufacturer-branded products ranging from personal care products (where PLs sell for 46 percent less on average) to refrigerated food (with a price differential of 16 percent). (Ibid)
} 
problem or reducing the (fixed) trade costs of direct market access. By contrast, in our model intermediaries pool their upstream suppliers' products, thus stripping manufacturer-specific identifiers from the product before it reaches the consumer.

The model incorporates micro-founded building blocks from earlier work to identify an intuitive, plausible, and general sorting mechanism by which firms of differing ex-ante product characteristics self select into export modes. The largest exporters ship products directly (perhaps by establishing a foreign wholesale subsidiary as in Felbermayr and Jung (2008)), while smaller exporters ship indirectly through intermediaries, and the smallest and least productive firms do not export at all.

The model highlights the important differences between two very different business models for trade intermediation: simple wholesaling, which would be preferred by larger exporters in more differentiated products (where manufacturers compete on brand-equity), versus pooledproducer contracts (where manufacturers compete on cost). We find that the availability of pooled-producer trade intermediation results in greater Home exports, which reduces the profits of the direct exporters and induces some former direct-exporters to switch to private label exporting. The net effect on the total number of home exporters is ambiguous: private label technology provides an additional mode of accessing the export market, leading to entry, but it simultaneously introduces a stark pro-competitive effect, pushing firms to exit. We show that the second effect dominates the first (i.e. there is net exit) when the intermediary's cost advantage over direct exporters is large, products are relatively less differentiated, or the exports from the rest of the world are large.

As in any trade model, one important aspect to consider is the effect of variations in trade cost. We analyze variations in both the variable and the fixed costs of exporting. And we do so in a synchronous fashion, that is varying trade costs in unison for both export channels, direct exporting and via the intermediary. We find that an increase in variable trade costs reduces the range of direct exporters and shifts the range of exporters who use the intermediary toward higher quality, so that the total range of exporting firms is reduced. As for the intensive margin, we show that the quantity exported by an individual exporter via the intermediary remains unchanged, while the individual direct exporter even exports more as there are fewer competing differentiated products. On net, the extensive margin dominates and total export volume falls with an increase in variable trade costs, as one would expect. An increase in the fixed cost directly impacts direct exporters, while the fixed cost of intermediation is born by the retailer itself. Still, there are indirect effects that impact both channels. The range of firms who use the intermediary increases, the range of direct exporters shrinks, while the effect on the total number of exporting firms is found to be ambiguous. In terms of the intensive margin, we find 
that a firm who uses intermediation exports more, while the net effects on total export volume and individual direct exports are ambiguous.

We then use the model to explore the implications of market power at the intermediation level, considering first the case where many retailers each offer (exclusive) access to a subset of destination market consumers, and second a scenario where the monopolist retailer faces potential entry and thus has to reduce the fee it sets to extract profit from exporting firms. While the results we obtain for the baseline model prove robust to the variation in market structure analyzed in the first scenario, a reduction in monopoly power due to potential entry does have substantial effects. Small reductions in the market power of the intermediary render exporting under its private label more attractive: while direct exports fall, private label and total exports increase. As the pricing power of the retailer vanishes further, however, the negative aspects of the private label start to dominate as lower quality exporters are absorbed into the private label pool, leading to an increase in direct exports and a decline in overall export volumes.

The paper makes three key contributions. First, by introducing the possibility that trade intermediation can pool products under a single brand, we identify potential negative effects of intermediation: reduced product differentiation and distortionary rent appropriation by the intermediary. While our model leads to the usual sorting according to exporting firms' productivity - least productive abstain, medium productivity firms choose intermediary, and high productivity firms export directly - the negative aspect gives rise to the possibility that the total number of exporting firms can decrease due to trade intermediation. Second, we find that the effects of reduced trade costs are potential complex. While a reduction in variable cost is straight-forward, the effects of a variation in fixed cost are more involved, as one aspect of trade intermediation is spreading the fixed cost over all the firms it sources from, while firms who export directly are affected one-for-one. Finally and perhaps interestingly, our analysis of a reduction in the retailer's monopsony power shows that it has non-monotone effects. In effect, there exists an optimal degree of market concentration - too much concentration and aggressive private label contracts crowd out direct exporters, too little and private labels resort to the lowest quality exporters, causing overall exports to fall.

Finally, it is important to note explicitly that our static model is by definition unable to capture the potential dynamic implications of intermediated trade, which may prove of central importance in practice. As the work of Bai, Krishna, and Ma (2012) makes clear, to the extent that direct exporters' are better able to learn and adapt to the foreign markets they serve, trade intermediation may impose additional dynamic costs to consumers, above and beyond the styptic welfare cost associated with loss of varieties.

The remainder of the paper proceeds in the usual sequence. The next Section presents 
the benchmark model with and without the private label export channel. Section 3 analyzes the effects of the availability of intermediated private label exporting. Section 4 offers policy-oriented comparative statics on trade costs, while Section 5 considers variations in market power. We conclude in Section 6.

\section{The Model}

We analyze an environment with (potentially) many Home firms that consider exporting to a Foreign country. Since we are interested in different modes of exporting behavior, we ignore the domestic market at Home and focus only on the target market abroad.

First we describe consumers in the exporters' target market. The Foreign market consists of a mass of $L$ consumers, each of whom has the following utility function:

$$
U=q_{0}^{c}+\alpha \int \lambda_{i} q_{i}^{c} d i-\frac{1}{2} \gamma \int\left(q_{i}^{c}\right)^{2} d i-\frac{1}{2} \eta\left(\int q_{i}^{c} d i\right)^{2},
$$

where $q_{0}^{c}$ is individual consumption of a numeraire good and $q_{i}^{c}$ is individual consumption of product $i{ }^{10}$ The resulting inverse market demand for product $i$ is linear:

$$
p_{i}=\lambda_{i} \alpha-\eta \frac{Q}{L}-\frac{\gamma q_{i}}{L}
$$

where $q_{i}$ is aggregate consumption of product $i$ and $Q$ is the aggregate consumption of all nonnumeraire products available in the marketplace. ${ }^{11}$

The Foreign market is served not only by Home firms, but also by the world at large; aggregate sales of differentiated goods by the rest of the world to the Foreign market are denoted by $Q^{W}$. Aggregate consumption in Foreign is then equal to $Q=Q^{W}+Q^{H}$, where $Q^{H}$ denotes aggregate exports to Foreign by Home firms. We assume that the Home country is sufficiently small that exports by Home firms do not affect world exports $Q^{W}$.

Next we describe Home firms. We assume a single factor of production - labor - and categorize firms into two sectors: a basic numeraire sector and the remaining differentiated goods sector. The numeraire good is produced under constant returns to scale with a unit cost, which implies a unit wage to labor. In the differentiated goods sector, all firms have the same constant marginal cost of production, denoted by $c$, but differ by an exogenous firm 'taste' parameter, $\lambda$, which can be interpreted as the inherent popularity of the product, quality, or any other

\footnotetext{
${ }^{10}$ This utility function is used in Ottaviano, Tabuchi, and Thisse (2002).

${ }^{11}$ Note the implicit assumption that every consumers' income is sufficient to ensure positive consumption of each differentiated product, $i$.
} 
firm-specific demand shifter. ${ }^{12}$ We will refer to a firm with a draw of $\lambda$ as a $\lambda$-type firm. We assume that $\lambda$ is distributed uniformly over the unit interval, $[0,1]$.

Each firm randomly draws its parameter $\lambda$ and then makes a decision whether to export or not. Two modes of exporting are available to Home firms. The first mode is direct exports (DE), by which a Home firm sets up a direct marketing link or storefront in the export market, selling its product directly to Foreign consumers under its original label. Direct exporting requires a fixed set-up cost equal to $F^{D E}$ as well as a per unit cost of $c^{D E}$. The second means by which to access the Foreign target market is via the distribution network of a multinational firm-retailer which we discuss in detail shortly.

\section{$2.1 \quad$ Direct Exports}

First, consider the case in which direct exports is the only mode of exporting available to Home firms. In this scenario, a $\lambda$-type firm solves the following profit-maximization problem:

$$
\max _{q}\left(\left(\lambda \alpha-\eta \frac{Q}{L}-\frac{\gamma q}{L}-c-c^{D E}\right) q-F^{D E}\right)
$$

where $Q=Q^{W}+Q^{H, D E}$ is the aggregate output sold in the foreign market which in this simple version of the model consists only of the foreign offering and units sold by Home firms via direct exporting. Following the literature, we assume that individual firms behave atomistically in the global market - taking aggregate quantity, $Q$, as fixed. The profit-maximizing output of a $\lambda$-type firm is then:

$$
q^{D E}(\lambda)=\frac{L}{2 \gamma}\left(\lambda \alpha-\eta \frac{Q}{L}-c-c^{D E}\right)
$$

with associated profit:

$$
\pi^{D E}(\lambda)=\frac{L}{4 \gamma}\left(\lambda \alpha-\eta \frac{Q}{L}-c-c^{D E}\right)^{2}-F^{D E}
$$

Setting the profit from the outside option (not exporting) to zero, we have that a $\lambda$-type firm optimally exports if and only if $\pi^{D E}(\lambda) \geq 0$. Thus, only firms with sufficiently popular products will choose to export. Defining $\lambda^{D E}$ to be the the threshold, zero profit exporter, we have implicitly:

$$
\lambda^{D E}=\frac{1}{\alpha}\left(2 \sqrt{\frac{\gamma F^{D E}}{L}}+\eta \frac{Q}{L}+c+c^{D E}\right) .
$$

\footnotetext{
${ }^{12}$ Demidova, Kee, and Krishna (2011) offer an empirical basis for using firm specific demand shocks, based on evidence from Bangladeshi apparel exporters.
} 
Aggregating over the set of exporting firms, $\lambda \in\left[\lambda^{D E}, 1\right]$, per capita output sold in the Foreign market equals:

$$
\begin{aligned}
\frac{Q}{L} & =\frac{Q^{W}}{L}+\frac{1}{L} \int_{\lambda^{D E}}^{1} q^{D E}(\lambda) d \lambda= \\
& =\frac{Q^{W}}{L}+\frac{1-\lambda^{D E}}{4 \gamma \alpha}\left(\frac{4}{\alpha} \sqrt{\frac{\gamma F^{D E}}{L}}+1-\lambda^{D E}\right)
\end{aligned}
$$

Using equations (3) and (4) we can derive the equilibrium level of $\lambda^{D E}$ which is equal to:

$$
\lambda^{D E}=1-\frac{1}{\alpha \eta}\left(\sqrt{D}-2 \sqrt{\frac{\gamma F^{D E}}{L}} \eta-2 \alpha^{3} \gamma\right),
$$

where:

$$
D \equiv 4 \eta^{2} \gamma\left(\frac{F^{D E}}{L}+\frac{\alpha^{3}}{\eta}\left(\frac{\alpha^{3} \gamma}{\eta}+\alpha-\frac{\eta Q^{W}}{L}-c-c^{D E}\right)\right) .
$$

To conclude the exposition of the model with only direct exporting, note the effects of increases in the costs of exporting, be it an increase in the fixed cost $F^{D E}$ or in the variable cost $c^{D E}$ :

$$
\begin{aligned}
\frac{d \lambda^{D E}}{d F^{D E}} & =\frac{\eta\left(1-\lambda^{D E}\right) \sqrt{\frac{\gamma}{L F^{D E}}}+2 \gamma \alpha^{2} \sqrt{\frac{\gamma}{L F^{D E}}}}{2 \gamma \alpha^{3}+\eta \alpha\left(1-\lambda^{D E}\right)+2 \eta \sqrt{\frac{\gamma F^{D E}}{L}}}>0, \\
\frac{d \lambda^{D E}}{d c^{D E}} & =\frac{2 \alpha^{2} \gamma}{\sqrt{D}}>0 .
\end{aligned}
$$

As one might expect, increasing either variable and fixed trade costs would lead to a higher threshold, reducing the range of exporting firms.

Regarding the intensive margin, we find:

$$
\begin{aligned}
\frac{d q^{D E}(\lambda)}{d F^{D E}} & =\frac{\eta}{\sqrt{D}}>0, \\
\frac{d q^{D E}(\lambda)}{d c^{D E}} & =-\frac{L \alpha^{3}}{\sqrt{D}}<0 .
\end{aligned}
$$

That is, an increase in the fixed cost increases the quantity exported per firm. This effect is driven entirely by the reduction in the range of domestic products that are exported and the resulting reduction in substitution possibilities in the foreign market. By contrast, a rise in variable trade cost reduces the quantity that is exported by an individual firm.

The aggregate quantity exported, finally, is reduced by an increase in either fixed or variable cost:

$$
\begin{aligned}
& \frac{d Q^{D E}}{d F^{D E}}=-\frac{2 \gamma}{\sqrt{D}}<0 \\
& \frac{d Q^{D E}}{d c^{D E}}=-2 \sqrt{\frac{\gamma L F^{D E}}{D}}-\frac{L \alpha\left(1-\lambda^{D E}\right)}{\sqrt{D}}<0 .
\end{aligned}
$$


This effect is clear for an increase in variable cost, as both the range of exporters and the quantity per firm decrease. The increase in fixed cost also leads to lower aggregate exports, as it reduces the mass of exporting firms while the increase in individual quantity is a secondary effect that is driven by the reduced range of substitutable products.

\subsection{International Retailer and Private Labels}

The second mode of exporting available to Home firms is via an international intermediary (IR) with an established distribution network which is already established in the Foreign target market. IR has a retailing/distributing technology that allows it to sell the products under a private label denoted by $k$. Consumers are assumed to be rational, risk-neutral and able to observe which firms supply under private label $k$. As such, consumers assign the expected quality $\lambda_{k}$ to a product sold under private label $k$ according to:

$$
\lambda_{k}=\frac{\int_{\Gamma} \lambda g(\lambda) d \lambda}{K}
$$

where $\Gamma$ and $K$ denote the set and measure, respectively, of firms that use the IR's distribution network.

Timing of the export distribution agreement is as follows. First, the retailer offers a contract $(\Delta, f)$ to all Home exporters, where $\Delta$ is a per unit fee and $f$ is a fixed fee paid by a Home firm to the IR. Then, Home firms decide whether to export directly, to accept a private label contract, or not to export at all.

We assume that the private label technology is costly for the retailer; that is, the IR needs to pay a fixed cost of $F_{R}$ (which will turn out to be of no effect) and a per unit cost of $c_{R}$ for each unit sold under the private label. Furthermore, we assume that the IR has a cost advantage in terms of variable cost compared to direct exporters, that is $c_{R}<c^{D E}$.

First, we find which Home firms choose a private label contract over direct exports for a given private label contract $(\Delta, f)$. The inverse demand for private label $k$ product is:

$$
p_{k}=\lambda_{k} \alpha-\eta \frac{Q}{L}-\frac{\gamma q_{k}}{L},
$$

where $q_{k}$ is an individual output of a private label exporter, while we denote by $Q_{k}^{H, P L}=K q_{k}$ the total output of all Home firms supplying under private label. The total output sold in the Foreign market when both channels - private label and direct exporting - are available then amounts to $Q=Q^{W}+Q^{H, D E}+Q_{k}^{H, P L}$.

The profit of a Home firm that accepts the private label contract is:

$$
\pi^{P L}=\left(\lambda_{k} \alpha-\eta \frac{Q}{L}-\frac{\gamma q_{k}}{L}-c-\Delta\right) q_{k}-f .
$$


The profit-maximizing output equals:

$$
q_{k}=\frac{L}{2 \gamma}\left(\lambda_{k} \alpha-\eta \frac{Q}{L}-c-\Delta\right)
$$

and the profit of a Home firm exporting under a private label contract is:

$$
\pi^{P L}=\frac{L}{4 \gamma}\left(\lambda_{k} \alpha-\eta \frac{Q}{L}-c-\Delta\right)^{2}-f
$$

It is both intuitive and straightforward to show that firms with high $\lambda$ choose to export directly, while firms with low $\lambda$ choose to export under the private label. To see this, note that $\pi^{D E}$ is strictly increasing in $\lambda$ while $\pi^{P L}$ is the same for all $\lambda$. Therefore, we have that Home firms with $\lambda \in(\bar{\lambda}, 1]$ are direct exporters and firms with $\lambda \in[\underline{\lambda}, \bar{\lambda}]$ export under the private label contract, where the upper threshold type, $\bar{\lambda}$, is implicitly given by:

$$
\pi^{D E}(\bar{\lambda})=\pi^{P L}
$$

and the $\underline{\lambda}$-type firm is the firm with the lowest $\lambda$ that accepts private label contract. Hence, the firms with $[0, \underline{\lambda})$ decide not to export at all.

Proposition 1 In equilibrium, there is a quality sorting where high quality firms export directly while low quality firms export under private label.

This result is consistent with the existing literature ${ }^{13}$ which predicts that low productivity firms use intermediaries to access export market. The difference so far is simply that in our model the sorting is along the quality dimension rather than productivity.

Next, note that if there are some firms that choose not to export at all (i.e., $\underline{\lambda}>0$ ) then we have:

$$
\pi^{P L}=0
$$

To see this, note that $\pi^{P L}$ cannot be negative since then no firms would accept the private label contract. Consider now $\pi^{P L}>0$. In this case, it becomes profitable for Home firms with $\lambda$ lower than $\underline{\lambda}$ to accept the private label contract. This reduces the average quality of the private label product $\lambda_{k}$, which in turn reduces the profit $\pi^{P L}$. Hence, $\pi^{P L}>0$ cannot obtain in equilibrium.

We focus on the case in which some firms choose not to export at all, so that $\underline{\lambda}>0$. In this case, using (8) we have that the output of a Home firm exporting under the private label contract is:

$$
q_{k}=\sqrt{\frac{L f}{\gamma}} .
$$

\footnotetext{
${ }^{13}$ See, e.g., Blum et al (2009), Felbermayr and Jung (2009), Akerman (2010).
} 
We can now characterize the range of the Home firms that choose the private label contract over direct exports. To do so we need to solve for $\underline{\lambda}, \bar{\lambda}$ and $K$. To find $\bar{\lambda}$ we use conditions (7) and (8) to get $\pi^{D E}(\bar{\lambda})=0$. We then have:

$$
\bar{\lambda}=\frac{1}{\alpha}\left(2 \sqrt{\frac{\gamma F^{D E}}{L}}+\eta \frac{Q}{L}+c+c^{D E}\right) .
$$

Then using condition (8) we can find $\lambda_{k}$ :

$$
\lambda_{k}=\frac{1}{\alpha}\left(2 \sqrt{\frac{\gamma f}{L}}+\eta \frac{Q}{L}+c+\Delta\right) .
$$

Finally, using $\lambda_{k}=\frac{\lambda+\bar{\lambda}}{2}$, we have that the measure of Home firms exporting under the private label equals:

$$
\begin{aligned}
K= & \bar{\lambda}-\underline{\lambda}=2\left(\bar{\lambda}-\lambda_{k}\right)= \\
& 2 \frac{1}{\alpha}\left(2 \sqrt{\frac{\gamma F^{D E}}{L}}-2 \sqrt{\frac{\gamma f}{L}}+c^{D E}-\Delta\right)
\end{aligned}
$$

As one would expect, a higher per unit fee $\Delta$ or a higher fixed fee $f$ charged by the IR decrease the measure of firms that accept a private label contract.

We are now ready to characterize the contract that maximizes the retailer's profit:

$$
\Pi=K q_{k}\left(\Delta-c_{R}\right)+K f-F_{R}
$$

Using (11), we have that:

$$
\Pi=2 \frac{1}{\alpha}\left(2 \sqrt{\frac{\gamma F^{D E}}{L}}-2 \sqrt{\frac{\gamma f}{L}}+c^{D E}-\Delta\right)\left(\left(\Delta-c_{R}\right) \sqrt{\frac{L f}{\gamma}}+f\right)-F_{R}
$$

Then the contract which maximizes the IR's profit is:

$$
\begin{aligned}
\Delta & =c_{r} \\
\sqrt{\frac{\gamma f}{L}} & =\frac{2}{3} \sqrt{\frac{\gamma F^{D E}}{L}}+\frac{1}{3} c^{D E}-\frac{1}{3} c_{r}
\end{aligned}
$$

Proposition 2 The equilibrium private label contract is

$$
\Delta=c_{r} \text { and } f=\frac{L}{\gamma}\left(\frac{2}{3} \sqrt{\frac{\gamma F^{D E}}{L}}+\frac{1}{3}\left(c^{D E}-c_{r}\right)\right)^{2}
$$

Therefore, the retailer charges per unit fee equal to its per unit cost of exporting and then chooses a fixed fee to extract all of the surplus from the Home private label exporters. This fixed fee $f$ is large if the Foreign market is large ( $L$ is large), the IR's cost advantage, $\left(c^{D E}-c_{r}\right)$, is large, or the fixed cost of exporting directly, $F^{D E}$, is large.

Next, using Proposition 2 and (11) we derive the equilibrium measure of Home firms which export under private label. 
Proposition 3 The measure of Home firms exporting under the private label is

$$
K=\frac{2}{\alpha}\left(\frac{2}{3} \sqrt{\frac{\gamma F^{D E}}{L}}+\frac{1}{3}\left(c^{D E}-c_{r}\right)\right) .
$$

Hence, there are more private label exporters in the markets where IR has a greater cost advantage, $\left(c^{D E}-c_{r}\right)$, or the fixed cost of reaching a foreign consumer by exporting directly, $\frac{F^{D E}}{L}$ is high, as in these cases direct exporting is a very costly option for Home firms and hence many of them choose exporting under private label. Also, there are more private label exporters in the export markets where $\alpha$ is low as consumers have less intense preferences for differentiated products.

Next, we can solve for the thresholds $\bar{\lambda}, \underline{\lambda}$ and the average $\lambda_{k}$. First, the per capita output sold in the target Foreign market is equal to

$$
\begin{aligned}
\frac{Q}{L} & =\frac{Q^{W}}{L}+\frac{1}{L}\left(\int_{\bar{\lambda}}^{1} q^{D E}(\lambda) d \lambda+K q_{k}\right) \\
& =\frac{Q^{W}}{L}+\frac{(1-(\underline{\lambda}+K))}{4 \gamma \alpha}\left(\frac{4}{\alpha} \sqrt{\frac{\gamma F^{D E}}{L}}+1-(\underline{\lambda}+K)\right)+\frac{2}{\alpha \gamma}\left(\frac{2}{3} \sqrt{\frac{\gamma F^{D E}}{L}}+\frac{1}{3} c^{D E}-\frac{1}{3} c_{r}\right)^{2}
\end{aligned}
$$

We can now use (12), (10), and $\underline{\lambda}=\bar{\lambda}-K$, to solve for the lower threshold $\underline{\lambda}$ :

$$
\underline{\lambda}=1-K-\frac{1}{\alpha \eta}\left(\sqrt{D-2 K^{2} \alpha^{4} \eta^{2}}-2 \eta \sqrt{\frac{\gamma F^{D E}}{L}}-2 \alpha^{3} \gamma\right)
$$

The upper threshold and average then follow in the obvious way.

\section{The effects of private labels on Home exporters}

In this section, we investigate the effects of the availability of the additional private label export channel on Home exporters. Suppose that initially Home firms can export only directly, which is the scenario we outlined in section 2.1. We can now explore what happens to the range of Home exporters, their individual output, and their profits when the international retailer with its private label retailing technology enters the scene.

First, we find that the availability of the additional private label export channel raises total Home exports. To see this, suppose that the opposite were true - that is, total Home exports decrease. Then, from (1) and (2) we would infer that the output and the profit of each direct exporter increase. Hence, $\bar{\lambda}$ would fall and there would be more direct exporters. As we would have more direct exporters, each of them exporting more, we would have that the total output of direct exporters rises. Adding (the new) exports under the new private label, total Home exports necessarily would be higher, which contradicts the initial premise. We therefore conclude that 
the total quantity $Q^{H}$ exported by Home country firms is higher when the private label contract is available.

Similarly, it is straightforward to see that $\bar{\lambda}>\lambda^{D E}$; that is, there will be fewer Home direct exporters. Given that total Home exports rise with the introduction of the private label option, by (1) and (2) we have that individual output and the profit of Home direct exporters is lower when the private label export channel is available. The following Proposition summarizes these results.

Proposition 4 The availability of a private label contract results in:

(i) greater total Home exports

(ii) fewer Home direct exporters,

(iii) lower individual output and reduced profit of Home direct exporters.

Furthermore, we are also interested in how the availability of the private label export channel affects the total number of Home exporters. Using (5) and (13) we can derive the following:

$$
\underline{\lambda}-\lambda^{D E}=\frac{K}{\alpha \eta}\left(\sqrt{\frac{D}{K^{2}}}-\sqrt{\frac{D}{K^{2}}-2 \alpha^{4} \eta^{2}}-\alpha \eta\right) .
$$

We see that $\underline{\lambda}>\lambda^{D E}$ iff

$$
\frac{D}{K^{2}}<\frac{(\alpha \eta)^{2}}{4}\left(1+2 \alpha^{2}\right)^{2}
$$

or, substituting for $K$ and $D$, the mass of exporting firms decreases iff:

$$
\frac{16\left(\frac{\gamma F^{D E}}{L}+\frac{\alpha^{3} \gamma}{\eta}\left(\frac{\alpha^{3} \gamma}{\eta}+\alpha-\left(\eta \frac{Q^{W}}{L}+c+c^{D E}\right)\right)\right)}{\left(\frac{2}{3} \sqrt{\frac{\gamma F^{D E}}{L}}+\frac{1}{3}\left(c^{D E}-c_{r}\right)\right)^{2}}<\left(1+2 \alpha^{2}\right)^{2},
$$

which is generally ambiguous as it depends on parametric assumptions. Condition (14) is likely to be satisfied when the international retailer's cost advantage, $\left(c^{D E}-c_{r}\right)$ is high, substitutability between varieties, $\eta$, is high, or the rest of the world's exports per foreign consumer, $\frac{Q^{W}}{L}$ are high, that is the Home country is small. We summarize this finding as follows:

Proposition 5 The availability of private label exporting can force lower productivity Home firms to exit the export market. This will occur if the IR's cost advantage, $\left(c^{D E}-c_{r}\right)$ is high, substitutability between varieties, $\eta$, is high, or the ROW exports per foreign consumer, $\frac{Q^{W}}{L}$ are high.

This last proposition shows that the effect of the availability of the private label export channel on the total mass of exporters is ambiguous. On the one hand, private label intermediation opens up an additional way of exporting and, hence, allows new Home firms to start exporting. 
On the other hand, it reduces product differentiation and therefore has a pro-competitive effect that works to reduce the set of Home exporters. The second effect dominates if direct exporting is sufficiently difficult for Home firms, either because the international retailer's cost advantage is large enough or because the competition among Home firms strong enough, that is the products are very close substitutes or the rest of the world is very large compared to the Home country.

\section{Variations in trade costs}

Let us now investigate the effects of variations in trade costs. Note that our analysis applies to both real trade costs as well as tariffs. The revenue that arises from a tariff does not affect our analysis as it accrues to the importing country, whereas the effects we analyze below play out in the exporting country.

\subsection{Variation in variable cost}

Consider first a variation in the variable trade $\operatorname{costs}\left(c^{D E}\right.$ and $\left.c_{R}\right)$. We want to consider in unison variations of both costs. That is, we consider $c^{D E}+t$ and $c_{R}+t$ and differentiate with respect to $t$, which is equivalent to varying a specific tariff that is independent of the distribution channel.

The effects of such a variation on the extensive margins are straightforward:

$$
\frac{d \underline{\lambda}}{d t}=\frac{d \bar{\lambda}}{d t}=\frac{2 \gamma \alpha^{2}}{\sqrt{D-2 K^{2} \alpha^{4} \eta^{2}}}>0
$$

That is, both the upper and lower cut-offs both move up by the same amount as the variable trade cost increases. The mass of firms that export via the retailer is unaffected, while the range of direct exporters is reduce

In order to understand the effect of increased variable trade costs on the intensive margin, we first need to know how the optimal contract offered by the retailer is affected. We find that:

$$
\frac{d \Delta}{d t}=1 \quad \text { and } \quad \frac{d f}{d t}=0
$$

That is, the increase in variable cost is passed on to retailers one-for-one, while the fixed component of the contract remains unaffected.

As for the intensive margin, we have:

$$
\frac{d q^{k}}{d t}=0
$$

Furthermore, we can calculate

$$
\frac{d Q}{d t}=-L \frac{2 \sqrt{\frac{\gamma F^{D E}}{L}}+(1-\bar{\lambda}) \alpha}{\sqrt{D-2 K^{2} \alpha^{4} \eta^{2}}}<0
$$


And, finally:

$$
\frac{d q^{D E}}{d t}=-\frac{\eta}{2 \gamma} \frac{d Q}{d t}-\frac{L}{2 \gamma}=\frac{\alpha^{3} L}{\sqrt{D-2 K^{2} \alpha^{4} \eta^{2}}}>0
$$

Private label exporters do not export more or less individually or as a group, whereas direct exporters individually increase their sale, but shrink in number. The extensive margin dominates, so that aggregate exports fall: In others words, similar to our comparative static results in subsection 2.1, the increase in quantity per direct exporter is a secondary effect, due entirely to the reduction in the number of available varieties in the destination market.

We summarize these findings in the following proposition:

Proposition 6 A uniform increase in variable trade cost leads to:

i) higher thresholds for private label exporters but no effect on mass nor output,

ii) a reduction in the mass of direct exporters, yet higher individual quantities,

iii) and lower aggregate exports.

\subsection{Variation in fixed cost trade costs}

We now focus on a variation in the fixed cost of exporting. As above, we would in principle want to consider a synchronous change both fixed costs, $F^{D E}$ and $F_{R}$. However, this turns out to be unnecessary, as the fixed cost of the retailer does not affect any of the results. So we can concentrate on varying $F^{D E}$, keeping in mind that this represents the uneven impact of varying both fixed costs in synchronous fashion.

We consider first the extensive margin, where we obtain the following comparative statics results:

$$
\begin{gathered}
\frac{d K}{d F^{D E}}=\frac{2}{3 \alpha} \sqrt{\frac{\gamma}{L F^{D E}}}>0 \\
\frac{d \underline{\lambda}}{d F^{D E}}=\frac{1}{3 \alpha} \sqrt{\frac{\gamma}{L F^{D E}}}-\frac{\frac{2 \eta \gamma}{L}-\frac{4}{3} K \alpha^{3} \eta \sqrt{\frac{\gamma}{L F^{D E}}}}{\alpha \sqrt{D-2 K^{2} \alpha^{4} \eta^{2}}}
\end{gathered}
$$

and

$$
\frac{d \bar{\lambda}}{d F^{D E}}=\frac{1}{\alpha} \sqrt{\frac{\gamma}{L F^{D E}}}-\frac{\frac{2 \eta \gamma}{L}-\frac{4}{3} K \alpha^{3} \eta \sqrt{\frac{\gamma}{L F^{D E}}}}{\alpha \sqrt{D-2 K^{2} \alpha^{4} \eta^{2}}} .
$$

Using equation (13) to obtain $1-\bar{\lambda}$ and substituting for this in $d \bar{\lambda} / d F^{D E}$ gives:

$$
\frac{d \bar{\lambda}}{d F^{D E}}=\frac{\sqrt{\frac{\gamma}{L F^{D E}}}}{\alpha \sqrt{D-2 K^{2} \alpha^{4} \eta^{2}}}\left((1-\bar{\lambda}) \alpha \eta+2 \alpha^{3} \gamma+\frac{4}{3} K \alpha^{3} \eta\right)>0
$$

So the mass of private label exporters increases and $\bar{\lambda}$ also increases as fixed costs of exporting rise: some previously direct exporters will switch to intermediated private label trade. 
Unfortunately, the same substition is not possible for $d \underline{\lambda} / d F^{D E}$. The sign of the effect on the lower cut-off depends on

$$
\frac{1}{3} \sqrt{D-2 K^{2} \alpha^{4} \eta^{2}}-2 \eta \sqrt{\frac{\gamma F^{D E}}{L}}+\frac{4}{3} K \alpha^{3} \eta \gtrless 0
$$

The effect on the total number of exporters is hence ambiguous.

In order to investigate the intensive margin, we first consider the effect on the optimal contract:

$$
\frac{d \Delta}{d F^{D E}}=0 \quad \text { and } \quad \frac{d f}{d F^{D E}}=\frac{4}{9}+\frac{2}{9}\left(c^{D E}-c_{R}\right) \sqrt{\frac{L}{\gamma F^{D E}}}>0 .
$$

That is, the variable part is not affected, but the retailer succeeds in extracting more profit via the fixed fee, as firms' outside option (direct exporting) becomes more costly. Turning to the intensive margin, we find that:

$$
\frac{d q^{k}}{d F^{D E}}=\frac{1}{3} \sqrt{\frac{L}{\gamma F^{D E}}}>0
$$

Each firm who chooses to use the retailer, exports more when the fixed cost of direct exporting increases. Since we already saw that the mass of these firms increases as well, total private label exports increase.

As for the effect on aggregate exports, we have that

$$
\frac{d Q}{d F^{D E}}=2 L\left(\frac{\sqrt{\frac{\gamma}{L F^{D E}}}}{\sqrt{D-2 K^{2} \alpha^{4} \eta^{2}}}\left(\frac{2}{3} K \alpha^{3}-\sqrt{\frac{\gamma F^{D E}}{L}}\right)\right)
$$

Hence $\frac{d Q}{d F^{D E}} \gtrless 0$ depending on

$$
\left(\frac{8}{9} \alpha^{2}-1\right) \sqrt{\frac{\gamma F^{D E}}{L}}+\frac{4}{9} \alpha^{2}\left(c^{D E}-c_{r}\right) \gtrless 0
$$

If $\alpha, \gamma F^{D E} / L$ or $\left(c^{D E}-c_{r}\right)$ are high then we see higher aggregate exports in response to an increase in the fixed cost of direct exports. And since

$$
\frac{d q^{D E}(\lambda)}{d F^{D E}}=-\frac{\eta}{2 \gamma} \frac{d Q}{d F^{D E}}
$$

we have the opposite effect on the individual quantity of each direct exporter, which is due to competition effects.

We summarize these findings in the following proposition:

Proposition 7 A uniform increase in the fixed cost of exporting leads to:

i) a higher mass and individual quantity of private label exporters;

ii) a lower mass of direct exporters; and 
iii) opposite effects on individual quantity of direct exporters and aggregate exports, where the respective direction depends on the demand intercept, the level of the per capita fixed cost, and the variable cost difference between both channels.

\section{$5 \quad$ Retailing Market Structure}

So far we have assumed in our model that the retailer is a monopolist. We now relax this assumption and consider alternative market structures in the retailing sector. The objective is to investigate the robustness of our results with regards to this assumption.

\section{$5.1 \quad \mathrm{~N}$ retailers each controlling $1 / \mathrm{N}$ of the market}

First, we show that the monopoly set-up is equivalent to a market structure where $\mathrm{N}$ retailers each control access to a segment of size $1 / \mathrm{N}$ of the market. That is, the $\mathrm{N}$ retailers each offer access to $L / N$ of Foreign consumers in the export market. In the interest of keeping the analysis tractable, we assume that all retailers have the same per unit $\operatorname{costs}$ of $\mathrm{c}^{R}$.

Consider retailer $k \in N$ who offers a private label contract of the form $\left(\Delta_{k}, f_{k}\right)$. Since this retailer offers access to to only $1 / \mathrm{N}$ of the market, the demand faced by a producer who exports under this contract is

$$
p_{k}=\lambda_{k} \alpha-\eta \frac{Q}{L}-\frac{\gamma q_{k}}{(L / N)}
$$

where $q_{k}$ is an individual quantity and $\mathrm{Q}$ is total exports in the Foreign market.

As in the baseline model, the profit of any firm that exports under the private label contract is zero

$$
\pi_{k}^{P L}=\frac{\gamma}{L / N}\left(q_{k}\right)^{2}-f_{k}=0
$$

The average quality of the private label $k$ and the individual output of a firm exporting under the private label are then

$$
\begin{aligned}
q_{k} & =\sqrt{\frac{f_{k} L}{\gamma N}} \\
\lambda_{k} & =\frac{1}{\alpha}\left(2 \sqrt{\frac{N f_{k} \gamma}{L}}+\eta \frac{Q}{L}+c+\Delta\right)
\end{aligned}
$$

As before, the profit of a firm choosing to export via retail intermediaries has to equal the profit of a direct exporter at the cut-off:

$$
N \pi_{k}^{P L}=\pi^{D E}(\bar{\lambda})=0
$$


It follows that the quality of the firm who is indifferent between exporting directly and under private label is given as:

$$
\bar{\lambda}=\frac{1}{\alpha}\left(2 \sqrt{\frac{\gamma F^{D E}}{L}}+\eta \frac{Q}{L}+c+c^{D E}\right) .
$$

Finally, the measure of private label $\mathrm{k}$ exporters is:

$$
K_{k}=2\left(\bar{\lambda}-\lambda_{k}\right)=\frac{2}{\alpha}\left(2 \sqrt{\frac{\gamma F^{D E}}{L}}-2 \sqrt{\frac{N f_{k} \gamma}{L}}+c^{D E}-\Delta\right) .
$$

Turning attention to the decision problem of the retailers, each retailer $k$ chooses the contract to maximize her profits:

$$
\Pi_{k}=K_{k} q_{k}\left(\Delta_{k}-c^{R}\right)+K_{k} f_{k}
$$

The contract that solves this maximization problem is:

$$
\begin{aligned}
\Delta_{k} & =c^{R} \\
f_{k} & =\frac{L}{9 N \gamma}\left(2 \sqrt{\frac{\gamma F^{D E}}{L}}+c^{D E}-c^{R}\right)^{2}
\end{aligned}
$$

The resulting measure of private label exporters is

$$
K_{k}=\frac{2}{3 \alpha}\left(2 \sqrt{\frac{\gamma F^{D E}}{L}}+c^{D E}-c^{R}\right)
$$

which is the same as in our benchmark model.

Importantly, note that each private label exporter supplies to all retailers and hence covers the whole market. Since the range of exporters supplying under private label is the same for every retailer, the average quality of each private label is also the same in each segment of the market.

Finally, the total quantity of private label exports is

$$
Q^{H, P L}=K N q^{k}=K N \sqrt{\frac{f_{k} L}{\gamma N}}=\frac{L}{\gamma} \frac{2}{9 \alpha}\left(2 \sqrt{\frac{\gamma F^{D E}}{L}}+c^{D E}-c^{R}\right)^{2} .
$$

The cut-off between private label and direct exporting is

$$
\bar{\lambda}=\frac{1}{\alpha}\left(2 \sqrt{\frac{\gamma F^{D E}}{L}}+\eta \frac{Q}{L}+c+c^{D E}\right)
$$

and total exports amount to

$$
\frac{Q}{L}=\frac{Q^{W}}{L}+\frac{1}{L}\left(\int_{\bar{\lambda}}^{1} q^{D E}(\lambda) d \lambda+Q^{H, P L}\right) .
$$

These results are the same as in our benchmark model; that is, they are robust to the variation in market structure we have considered in this subsection. This result should not be surprising - 
segmenting a symmetric market among multiple symmetric intermediaries does not reduce their market power relative to direct exporters, and so there are no meaningful changes to private label contract terms or, thus, market outcomes.

\subsection{Reducing monopoly power}

We now consider a reduction in the monopoly power of the (single) retailer. Suppose its market power is reduced, say due to potential entry. This competitive pressure decreases the retailing fee $f$ that the retailer can charge from Home exporters. The fee is therefore lower than in the monopoly case:

$$
f<\frac{L}{\gamma}\left(\frac{2}{3} \sqrt{\frac{\gamma F^{D E}}{L}}+\frac{1}{3} c^{D E}-\frac{1}{3} c_{r}\right)^{2}
$$

whereas the per unit fee of retailing remains the same, and equals the marginal cost of the retailer:

$$
\Delta=c^{R}
$$

The profit of a private label exporter in this case amounts to

$$
\pi^{P L}=q_{k}^{2} \frac{\gamma}{L}-f
$$

and we continue to assume that the fixed fee $f$ is sufficiently high so that there are some Home firms who do not export at all. The profit of private label exporters must thus be equal to zero,

$$
\pi^{P L}=q_{k}^{2} \frac{\gamma}{L}-f=0
$$

and each private label exporter's output equals

$$
q_{k}=\sqrt{\frac{f L}{\gamma}}
$$

Note that as the monopoly power of the retailer is reduced, the fixed fee $f$ decreases, and each private label exporter will export less - that is, $q_{k}$ decreases. Fundamentally, this reduction in the intensive margin is caused by the increase in the set of private label exporters, which we now demonstrate.

Next, we determine the measure of private label exporters and their total exports. Since profits have to be equal at the threshold, and private label exporters make zero profit, i.e. $\pi^{D E}(\bar{\lambda})=\pi^{P L}=0$, it follows that

$$
\bar{\lambda}=\frac{1}{\alpha}\left(2 \sqrt{\frac{\gamma F^{D E}}{L}}+\eta \frac{Q}{L}+c+c^{D E}\right),
$$


and

$$
\lambda_{k}=\frac{1}{\alpha}\left(2 \sqrt{\frac{\gamma f}{L}}+\eta \frac{Q}{L}+c+c^{R}\right) .
$$

The measure of Home firms exporting under the private label then equals:

$$
K=\bar{\lambda}-\underline{\lambda}=2\left(\bar{\lambda}-\lambda_{k}\right)=2 \frac{1}{\alpha}\left(2 \sqrt{\frac{\gamma F^{D E}}{L}}-2 \sqrt{\frac{\gamma f}{L}}+c^{D E}-c^{R}\right)
$$

As $f$ decreases, $K$ increases and there will be more private label exporters compared to the monopoly case. Thus, there are more private label exporters, but each one exports less individually.

The net effects on the total volume of intermediated exports takes some work. Given the mass of private label exporters, total private label exports amount to:

$$
Q^{H, P L}=K q_{k}=2 \frac{1}{\alpha}\left(2 \sqrt{\frac{\gamma F^{D E}}{L}}-2 \sqrt{\frac{\gamma f}{L}}+c^{D E}-c^{R}\right) \sqrt{\frac{f L}{\gamma}}
$$

and this quantity varies with the fixed retailing fee according to:

$$
\frac{d Q^{H, P L}}{d f}=\frac{1}{\alpha \sqrt{f}}\left(\left(2 \sqrt{\frac{\gamma F^{D E}}{L}}+c^{D E}-c^{R}\right) \sqrt{\frac{L}{\gamma}}-4 \sqrt{f}\right)
$$

In order to sign this derivative it proves convenient to define the following critical value of the fee: ${ }^{14}$

$$
\tilde{f}=\frac{L}{\gamma}\left(\frac{2 \sqrt{\frac{\gamma F^{D E}}{L}}+c^{D E}-c^{R}}{4}\right)^{2}
$$

Regarding the effect on the total quantity of private label exports, we have that for $f>\tilde{f}$ the quantity increases as $f$ falls, and then, once $f<\tilde{f}$, starts to decrease as the fee falls even further.

The resulting equilibrium is given by:

$$
\pi^{D E}(\lambda)=\frac{L}{4 \gamma}\left(\bar{\lambda} \alpha-\eta \frac{Q}{L}-c-c^{D E}\right)^{2}-F^{D E}=0
$$

and

$$
\begin{aligned}
& \frac{Q}{L}= \frac{Q^{W}}{L}+\frac{Q^{H, D E}}{L}+\frac{Q^{H, P L}}{L}= \\
& \frac{Q^{W}}{L}+\frac{(1-\bar{\lambda})}{4 \gamma \alpha}\left(\frac{4}{\alpha} \sqrt{\frac{\gamma F^{D E}}{L}}+1-\bar{\lambda}\right)+ \\
& 2 \frac{1}{\alpha}\left(2 \sqrt{\frac{\gamma F^{D E}}{L}}-2 \sqrt{\frac{\gamma f}{L}}+c^{D E}-c^{R}\right) \sqrt{\frac{f L}{\gamma}}
\end{aligned}
$$

${ }^{14}$ Note that $\widetilde{f}<\frac{L}{\gamma}\left(\frac{2}{3} \sqrt{\frac{\gamma F D E}{L}}+\frac{1}{3} c^{D E}-\frac{1}{3} c_{r}\right)^{2}$. 
We want to understand how these equilibrium values change when $f$ falls. Consider first the case where $f>\widetilde{f}$. For this range of market power we have that $\frac{Q}{L}$ and $\bar{\lambda}$ increase as $f$ falls. To see this, suppose that $\frac{Q}{L}$ decreases. Then $\bar{\lambda}$ decreases as well, which results in higher $Q^{H, D E}$. As $Q^{H, P L}$ also increases, $\frac{Q}{L}$ would rise, which is a contradiction. Now consider the case where $f<\tilde{f}$. In this range, $Q^{H, P L}$ decreases as $f$ falls and $\bar{\lambda}$ decreases as well. The argument is the same as before, only with opposite signs. We first summarize these results before turning to the intuition:

Proposition 8 As the market power of the retailer is reduced, that is, as $f$ decreases:

(i) if $f>\widetilde{f}$, then total exports rise, direct exports fall, private label exports rise, and the the measure of the direct exporters decreases

(ii) if $f<\tilde{f}$ then total exports decrease, direct exports rise, private label exports fall, and the the measure of the direct exporters increases.

The intuition for this result is as follows. The reduction of the fee clearly has a direct positive effect on the profitability of private label exporting. At first, when $f$ is very high, this effect dominates such that intermediated private label exports rise and direct exports fall. But notice, too, that abstracting from cost considerations, private label exporting is otherwise less attractive than direct exporting. Thus, starting from a lower fee (below the critical value defined above), a further decrease in $f$ will induce higher quality exporters to revert to direct exporting, as every lower quality exporters are brought under the private label contract. ${ }^{15}$

\section{Conclusion}

In this paper, we study the role of intermediation in international trade. In particular, we identify the potential importance of pooled or 'private label' contracts in shaping not just the extent of market access — which firms manage to export overseas — but also the nature of traded goods - how the intermediation process itself affects the range of differentiated products. In line with the existing literature, our model implies a sorting of potential exporters according to their productivity: low productivity firms do not export, medium productivity firms export via the intermediated private label channel, and high productivity firms prefer to export directly, as they would in the absence of this type of trade intermediation. The model we propose predicts that the availability of the additional channel to access the export market increases the volume of total exports of Home country firms. This comes at the expense of direct exporters, who

\footnotetext{
${ }^{15}$ Note that as $\mathrm{f}$ decreases, the quality of the lowest quality private label exporter also falls, and for sufficiently low $\mathrm{f}$ all Home producers start to export, that is $\underline{\lambda}=0$..
} 
reduce their individual quantity, partly switch to exporting under the private label or even leave the market.

As is standard in a trade paper, we investigate the effects of variations in trade costs. Since we are interested in comparing the (possibly divergent) effects on both channels of exporting, we consider a synchronous increase in either the fixed or variable cost of trade. For an increase in variable costs, we find that the range of private label exporters shifts up toward higher quality exporters, while the number of direct exporters falls. And while the individual quantity of firms who make use of the private label contract remains unaffected, the anti-competitive effect of the increase in trade costs allows the remaining direct exporters to increase firm-level exports due to a reduction in the range of competing differentiated products. An increase in fixed costs increases the cost of direct exporting relative to intermediation. As a result, the range of private label exporters increases, while the number of direct exporters declines. And while firms who use the private label also produce more, the effect on direct exporters is ambiguous, leading to an ambiguous effect on total exports.

Relaxing our assumption of a single retailer, we also consider the implications of market structure at the intermediary level for the equilibrium pattern of firm level exports and trade; that is, how competition among the trade middlemen can have important implications for producers and consumers on both ends of the shipping route. We find that when $\mathrm{N}$ retailers each control access to $1 / \mathrm{N}$ of the destination market, our results remain unchanged. However, when we consider a decrease in market power leading to a reduction in the fee the (single) retailer charges, we find non-monotone effects. At first total exports rise as the fee falls but eventually the effect turns negative, as the lowest quality exporters join the private label pool, enabling direct exporters to regain market share.

Besides constituting one important aspect of trade intermediation, the use of a private labels is relevant in a broader context as well. If one considers the relationship between mark-ups and product differentiation, the presence of private labels suggests one reason for a positive correlation. This in turn is important in the context of recent contributions to the trade literature that study the welfare gains from trade in the presence of differentiated products.

\section{References}

ACNiELSEn (2005): "The power of private label," Executive News Report from ACNielsen Global Services, September 2005.

Ahn, J., A. Khandelwal, and S.-J. Wei (2012): “The Role of Intermediaries in Fascilitating 
Trade," Journal of International Economics, forthcoming.

Akerman, A. (2010): "A Theory on the Role of Wholesalers in International Trade based on Economies of Scope," Research Papers in Economics 2010:1 Stockholm University Department of Economics.

Antràs, P., And A. Costinot (2011): "Intermediated Trade," The Quarterly Journal of Economics, 126, 1319-1374.

Bai, X., K. Krishna, and H. Ma (2012): "How You Export Matters: Export Mode, Learning and Productivity in China," Working Paper.

Basker, E., And P. H. VAn (2010a): "Imports R Us: Retail Chains as Platforms for Developing Country Imports," American Economic Review, Papers $\& 3$ Proceedings, 100(2), 414-418.

(2010b): "Putting a Smiley Face on the Dragon: Walmart as Catalyst to U.S.-China Trade," manuscript.

Bergès-Sennou, F., P. Bontems, and V. RÉquillart (2004): "Economics of Private Labels: A Survey of Literature," Journal of Agricultural and Food Industrial Organization, 2(3).

Bernard, A., E. Blanchard, H. Vandenbussche, and I. VanBeveren (2012): "CarryAlong Trade," manuscript.

Bernard, A. B., J. B. Jensen, S. J. Redding, and P. K. Schott (2010): "Wholesalers and Retailers in U.S. Trade (Long Version)," NBER Working Paper 15660.

Blum, B., S. Claro, and I. Horstmann (2010): "Facts and Figures on Intermediated Trade," American Economic Review, Papers 8 Proceedings, 100, 419-423.

DAsGupta, K., And J. Mondria (2011): "Quality Uncertainty and Intermediation in International Trade," manuscript.

Demidova, S., H. L. Kee, and K. Krishna (2011): "Do Trade Policy Differences Induce Sorting? Theory and Evidence from Bangladeshi Apparel Exporters," Working Paper.

Feenstra, R., and G. Hanson (2004): "Intermediaries and Entrôpot Trade: Hong Kong Re-export of Chinese Goods," Journal of Economics and Management Strategy, 13(1), 3-35.

Felbermayr, G., And B. Jung (2008): "Trade Intermediaries, Incomplete Contracts, and the Choice of Export Modes," Tübinger Diskussionsbeitrag no. 317. 
(2009): "Trade Intermediation and the Organization of Exporters," Hohenheimer Diskussionsbeiträge 309/2009.

Gabrielsen, T. StaAhl, and L. Sörgard (2007): "Private Labels, Price Rivalry, and Public Policy," European Economic Review, 51, 403-424.

Head, K., R. Jing, and D. Swenson (2010): "From Beijing to Bentonville: Do Multinational Retailers Link Markets," NBER Working Paper 16288.

Iacovone, L., B. Javorcik, W. Keller, and J. Tybout (2011): "Supplier Responses to Wal-Mart's Invasion in Mexico," NBER Working Paper No. 17204.

Mills, D. E. (1995): "Why Retailers Sell Private Labels," Journal of Economics and Management Strategy, 4, 509-528.

Ottaviano, G., T. Tabuchi, and J.-F. Thisse (2002): "Agglomeration and Trade Revisited," International Economic Review, 43(2), 409-435.

Private.Label.Magazine (2011): “Top 50 Retailers and Wholesalers," (March) E.W. Williams Publication Company, Fort Lee, N.J.

RAuCh, J., AND J. WATSON (2004): "Network Intermediaries in International Trade," Journal of Economics and Management Strategy, 13(1), 69-93. 